\title{
Prevalence of osseous changes of the temporomandibular joint in CBCT images of patients with and without temporomandibular disorders
}

\author{
Shahriar Shahab', Zeynab Azizi ${ }^{2}$, Farnaz Taghavi Damghani* and Farnoosh Taghavi Damghani ${ }^{4}$ \\ ${ }^{1}$ Assistant Professor, Department of Oral \& Maxillofacial Radiology, Shahed Dental School, Tehran, Iran \\ ${ }^{2}$ Assistant Professor, Department of Oral \& Maxillofacial Radiology, Shahed Dental School, Tehran, Iran \\ ${ }^{3}$ Dentist, Shahed Dental School, Tehran, Iran \\ ${ }^{4}$ Assistant Professor, Department of Prosthodontics, Shahid Beheshti University of Medical Sciences, Dental \\ School, Tehran, Iran
}

\begin{abstract}
Radiographic examinations are a part of routine clinical examination of temporomandibular disorders (TMD) to verify degenerative bone changes in the joint structures. Assessment of the prevalence of osseous changes of the temporomandibular joint (TMJ) in CBCT images of the patients with and without temporomandibular disorders.CBCT images of temporomandibular joint were taken in 62 patients with temporomandibular disorders and 62 patients without TMD. The presence of bone changes including flattening, erosion, subcortical sclerosis, osteophyte, subcortical cyst, condylar hyperplasia and condylar hypoplasia of temporomandibular joint were studied at left and right sides on CBCT images. Furthermore, clinical findings in relation to temporomandibular disorders in patients were obtained from their records. The prevalence of bone changes and clinical findings in the 2 group of patients were analyzed. Radiographic findings in the right TMJ of TMD patients, included erosion (27.4\%), osteophyte (17.7\%), subcortical sclerosis (16.1\%), condyle hyperplasia (6.5\%) and flattening (40.3\%). The prevalence of these bone changes in the right TMJ of non-TMD patients were 35.5, 6.5, 3.2, 0 and $37.1 \%$, respectively. In the left side of TMD group; erosion was found in $29.0 \%$, osteophyte $12.9 \%$, subcortical sclerosis $12.9 \%$, condyle hyperplasia $6.5 \%$ and flattening in $37.1 \%$ of the patients. The incidence of these changes in the same side of non- TMD group was 22.6, 3.2, 1.6, 0 and 32.3\%, respectively. Significant differences were found for osteophyte incidence in the left TMJ(P=0.04), subcortical sclerosis in the right $\operatorname{TMJ}(\mathrm{P}=0.02)$, subcortical sclerosis in the left $\operatorname{TMJ}(\mathrm{P}=0.02)$ and condylar hyperplasia in both joints $(\mathrm{P}=0.04)$ between TMD and non-TMD patients.The most prevalent bone changes related to temporomandibular disorders included flattening, erosion and osteophyte. The changes were highly reported for temporomandibular disorders than healthy individuals and no significant correlation was found between TMJ bone changes and the patients' age and gender.
\end{abstract}

KEY WORDS: BONY CHANGES, CONDYLE, CONE BEAM COMPUTED TOMOGRAPHY, TEMPOROMANDIBULAR JOINT, TEMPOROMANDIBULAR JOINT DISORDERS

ARTICLE INFORMATION:

*Corresponding Author: ftaghavi6@yahoo.com

Received $12^{\text {th }}$ June, 2017

Accepted after revision $18^{\text {th }}$ Sep, 2017

BBRC Print ISSN: 0974-6455

Online ISSN: 2321-4007 CODEN: USA BBRCBA

Thomson Reuters ISI ESC and Crossref Indexed Journal

NAAS Journal Score 2017: 4.31 Cosmos IF: 4.006

- A Society of Science and Nature Publication, 2017. All rights reserved.

Online Contents Available at: http//www.bbrc.in/

DOI: $10.21786 / \mathrm{bbrc} / 10.3 / 27$ 


\section{INTRODUCTION}

Temporomandibular disorders (TMD) are well defined as classification of abnormality including masticatory muscles, osseous and ligamentous components of the temporomandibular joints (TMJ) and neurological disease of this complex. The most common clinical signs of the TMDs are joint and muscle pain, mouth-opening limitation, crepitation and clicking. TMDs are frequently associated with degenerative bone changes involving the bone structures of the temporomandibular joint (TMJ) including flattening, osteophyte, erosion, subcortical sclerosis and pseudocysts, (Dos Anjos Pontual et al. 2012 De Melo et al. 2014, Ladeira et al. 2015 and Khojastepour et al. 2017).

Knowledge about these bone changes is fundamental for correctly diagnosing the dysfunctions associated with the disease and for appropriate treatment planning (Alexiou et al. 2009). Diagnostic procedure in patients with TMJ disorders includes the background, physical examination and other diagnostic processes such as imaging of the TMJ (Ludlow et al. 2008). A panoramic radiograph is often taken to assess the general condition of the teeth and structures of the maxilla and the mandible. To obtain more detailed information about the bony structures of the TMJ, other radiographs including computed tomography (CT) scans, and magnetic resonance images (MRI) can be taken which the latter gives information about the articular disc and the surrounding soft tissues (Honey et al. 2007). A relatively new imaging technique is cone-beam computed tomography (CBCT) and enables 3D imaging of bony structures of the skull, including the mandible and the TMJ (De Boer et al. 2014 Khojastepour et al. 2017).

The diagnostic accuracy of CBCT in detecting condylar osseous abnormalities was similar to CT images, while the sensitivity of CBCT in the detection of these abnormalities was higher (Wiese et al. 2011). The CBCT is more accurate than panoramic radiographs for the assessment of bone components of the TMJ (Ladeira et al. 2015). It is reported that the diagnostic properties of the CBCT in assessing bony conditions, is better than other existing imaging techniques. However, to date limited information exists on the role of CBCT in clinical decision-making in diagnosis or management of disorders of the TMJ (Krishnamoorthy et al. 2013). So, the aim of the current study was to determine the prevalence of osseous changes of the TMJ in CBCT images of the patients with and without TMD.

\section{MATERIALS AND METHODS}

In a descriptive cross-sectional trial, CBCT images of TMJ in 62 TMD-patients and 62 non-TMD patients (older than 17 years old) were obtained from 2 radiology centers and 3 dental clinics in Tehran, Iran during 2016-2017. The presence of bone changes of flattening, erosion, subcortical sclerosis, osteophyte, subcortical cyst, condylar hyperplasia and hypoplasia of TMJ were studied at left and right sides on CBCT images. In the TMD group the clinical evidences, and their correlation with sex and age were determined. The CBCT images of changes in flattening, osteophyte, erosion and subcortical cyst is presented in figures 1-4. Furthermore,

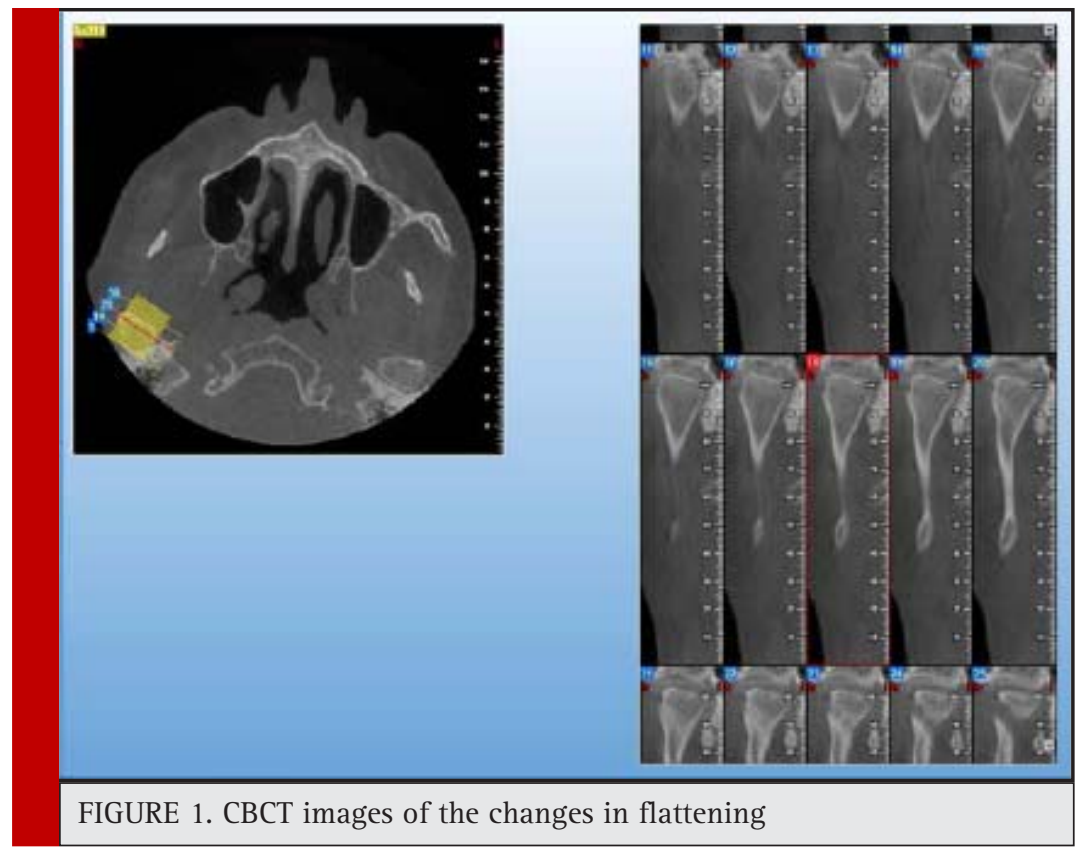




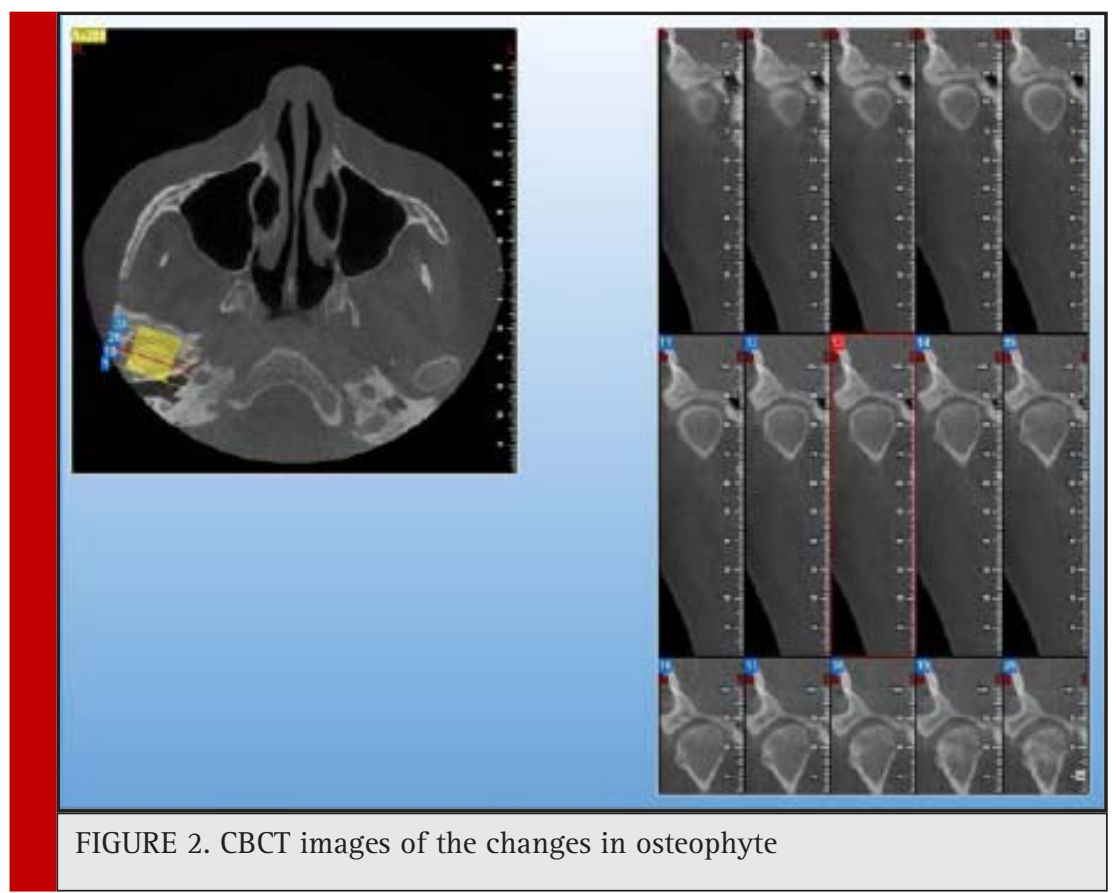

clinical findings in relation to TMD in TMD-patients were obtained from their records. The prevalence of bone changes and clinical findings in 2 TMD and nonTMD patients were analyzed using SPSS statistical software ver. 22 by Mann-Whitney U test. The correlation between bone changes and factors of age and gender were also determined by Spearman correlation ratio. $\mathrm{P}<0.05$ was considered as significant difference.
The CBCT images of changes in flattening, osteophyte, erosion and subcortical cyst is presented in figures 1-4.

\section{RESULTS AND DISCUSSION}

In this study in the right TMJ of TMD-patients; erosion has been found in 27.4\% (17 patients), osteophyte in $17.7 \%$ (11 patients), subcortical sclerosis in $16.1 \%$ (10

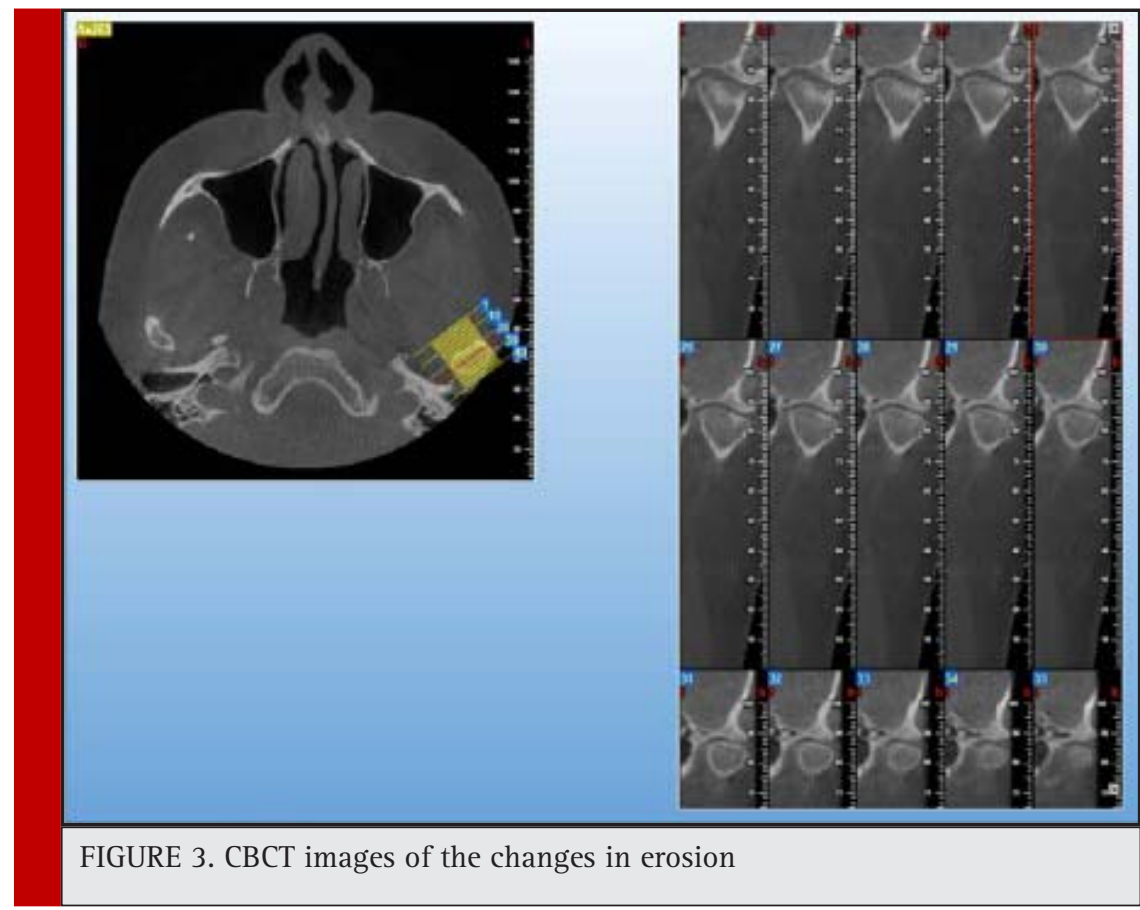




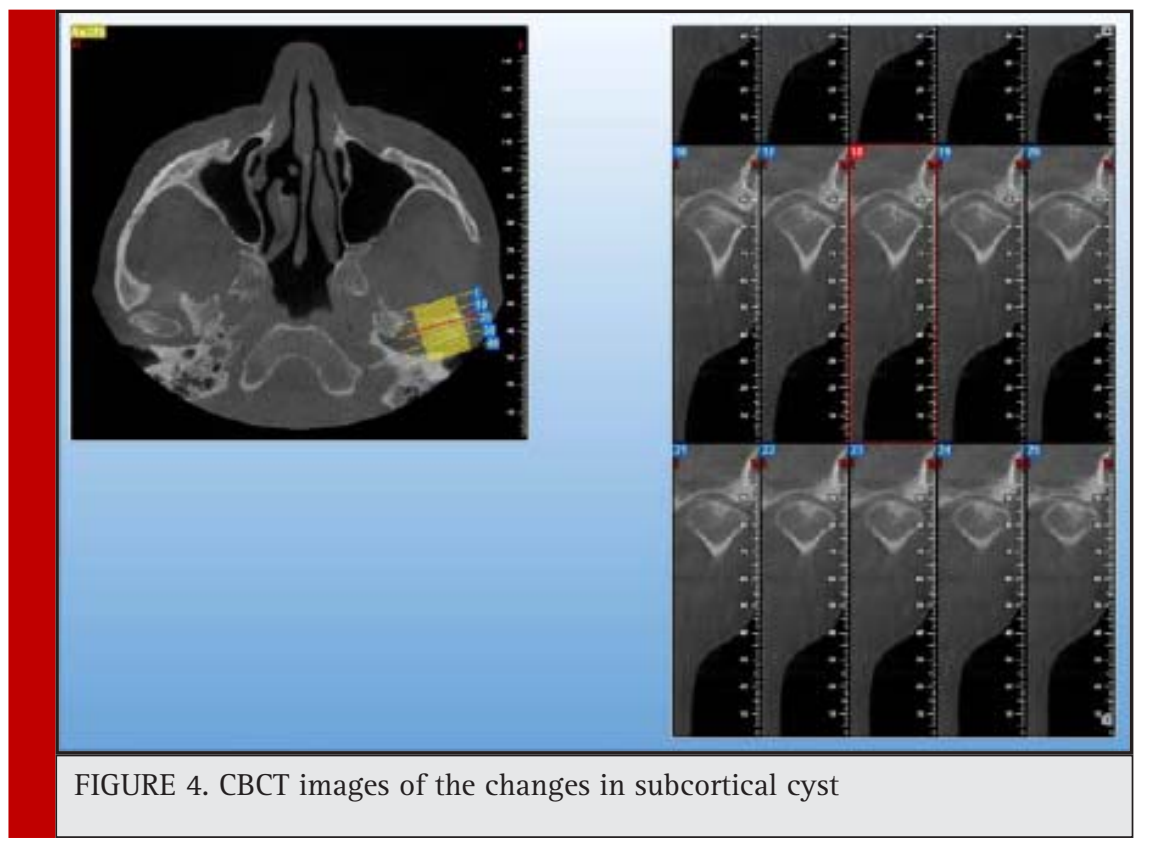

patients), condylar hyperplasia in $6.5 \%$ (4 patients) and flattening in $40.3 \%$ ( 25 patients). The prevalence of these bone changes in the right TMJ of non-TMD patients was 35.5\% (22 patients), 6.5\% (4 patients), 3.2\% (2 patients), 0 and $37.1 \%$ (23 patients) respectively.

In the left TMJ of TMD-patients; erosion was reported in $29.0 \%$ (18 patients), osteophyte in $12.9 \%$ (8 patients), subcortical sclerosis in $12.9 \%$ (8 patients), condyle hyperplasia in 6.5\% (4 patients) and flattening in 37.1\% (23 patients). The incidence of these changes in the left TMJ of non-TMD patients were also 22.6\% (14 patients), $3.2 \%$ ( 2 patients), 1.6\% (1 patients), 0 and 32.3\% (20 patients), respectively.

Significant differences were found regarding osteophyte incidence in the left TMJ $(\mathrm{P}=0.04)$, subcortical sclerosis in the right TMJ $(\mathrm{P}=0.02)$, subcortical sclerosis in the left TMJ $(\mathrm{P}=0.02)$ and condyle hyperplasia in both left and right TMJs (both: $\mathrm{p}=0.04$ ) in TMD and non-TMD patients.

As seen in tables 1and 2, in left TMJ pain was reported in $30(48.4 \%)$ patient and in the right TMJ in 27 (43.5\%), joint tenderness was also observed in 2 (3.2\%) patients.

\begin{tabular}{|c|c|c|c|}
\hline \multirow[t]{2}{*}{ Group } & Sex & right & left \\
\hline & Male & $7(50 \%)$ & $5(35.7 \%)$ \\
\hline \multirow[t]{3}{*}{ Case } & Female & $23(47.9 \%)$ & $22(45.8 \%)$ \\
\hline & Total & 30 (48.4\%) & $27(43.5 \%)$ \\
\hline & Male & $0(0 \%)$ & $0(0 \%)$ \\
\hline \multirow[t]{2}{*}{ Control } & Female & $0(0 \%)$ & $0(0 \%)$ \\
\hline & Total & $0(0 \%)$ & $0(0 \%)$ \\
\hline
\end{tabular}

\begin{tabular}{|c|c|c|}
\hline \multirow{2}{*}{ Group } & Sex & right \\
\hline & Male & $1(7.1 \%)$ \\
\hline \multirow[t]{3}{*}{ Case } & Female & $1(2.1 \%)$ \\
\hline & Total & $2(3.2 \%)$ \\
\hline & Male & $0(0 \%)$ \\
\hline \multirow[t]{2}{*}{ Control } & Female & $0(0 \%)$ \\
\hline & Total & $0(0 \%)$ \\
\hline
\end{tabular}

According to table 3, muscle tenderness was observed in $4(6.5 \%)$ patients at the right side and in 2cases (3.2\%) at left.

\begin{tabular}{|c|c|c|c|}
\hline \multicolumn{4}{|c|}{$\begin{array}{l}\text { Table 3. the frequency and percentage of } \\
\text { muscle tenderness in TMD and control patients }\end{array}$} \\
\hline Group & Sex & right & left \\
\hline & Male & $1(7.1 \%)$ & $1(7.1 \%)$ \\
\hline \multirow[t]{3}{*}{ Case } & Female & $3(6.3 \%)$ & $1(2.1 \%)$ \\
\hline & Total & $4(6.5 \%)$ & $2(3.2 \%)$ \\
\hline & Male & $0(0 \%)$ & $0(0 \%)$ \\
\hline \multirow[t]{2}{*}{ Control } & Female & $0(0 \%)$ & $0(0 \%)$ \\
\hline & Total & $0(0 \%)$ & $0(0 \%)$ \\
\hline
\end{tabular}

The deviation in opening in right and left sides were detected in $1(1.6 \%)$ and $1(1.6 \%)$ patients, respectively. 


\begin{tabular}{|c|c|c|c|}
\hline \multirow[t]{2}{*}{ Group } & Sex & right & left \\
\hline & Male & $0(0 \%)$ & $1(7.1 \%)$ \\
\hline \multirow[t]{3}{*}{ Case } & Female & $1(2.1 \%)$ & $0(0 \%)$ \\
\hline & Total & $1(1.6 \%)$ & $1(1.6 \%)$ \\
\hline & Male & $0(0 \%)$ & $0(0 \%)$ \\
\hline \multirow[t]{2}{*}{ Control } & Female & $0(0 \%)$ & $0(0 \%)$ \\
\hline & Total & $0(0 \%)$ & $0(0 \%)$ \\
\hline
\end{tabular}

Limitation in right and left sides was observed in 13 (21\%) patients (table 5).

Table 5. the frequency and percentage of limitation in case and control patients

\begin{tabular}{|l|l|l|l|}
\hline Group & Sex & right & left \\
\hline & Male & $4(28.6 \%)$ & $4(28.6 \%)$ \\
\hline Case & Female & $9(18.8 \%)$ & $9(18.8 \%)$ \\
\hline & Total & $13(21 \%)$ & $13(21 \%)$ \\
\hline & Male & $0(0 \%)$ & $0(0 \%)$ \\
\hline Control & Female & $0(0 \%)$ & $0(0 \%)$ \\
\hline & Total & $0(0 \%)$ & $0(0 \%)$ \\
\hline
\end{tabular}

Clicking in right and left sides was detected in 26 (41.9\%) and 30 (48.4\%) patients, respectively (table 6).

\begin{tabular}{|c|c|c|c|}
\hline \multicolumn{4}{|c|}{$\begin{array}{l}\text { Table 6. the frequency and percentage of } \\
\text { clicking in case and control patients }\end{array}$} \\
\hline Group & Sex & right & left \\
\hline & Male & $5(35.7 \%)$ & $5(35.7 \%)$ \\
\hline \multirow[t]{3}{*}{ Case } & Female & $21(43.8 \%)$ & $25(52.1 \%)$ \\
\hline & Total & $26(41.9 \%)$ & $30(48.4 \%)$ \\
\hline & Male & $0(0 \%)$ & $0(0 \%)$ \\
\hline \multirow[t]{2}{*}{ Control } & Female & $0(0 \%)$ & $0(0 \%)$ \\
\hline & Total & $0(0 \%)$ & $0(0 \%)$ \\
\hline
\end{tabular}

The crepitus occurrence in left and right sides in patients were $3(4.8 \%)$ and 1 (1.6\%), respectively.

Table 7. the frequency and percentage of crepitus in case and control patients

\begin{tabular}{|l|l|l|l|}
\hline Group & Sex & right & left \\
\hline & Male & $0(0 \%)$ & $0(0 \%)$ \\
\hline Case & Female & $1(2.1 \%)$ & $3(6.3 \%)$ \\
\hline & Total & $1(1.6 \%)$ & $3(4.8 \%)$ \\
\hline & Male & $0(0 \%)$ & $0(0 \%)$ \\
\hline Control & Female & $0(0 \%)$ & $0(0 \%)$ \\
\hline & Total & $0(0 \%)$ & $0(0 \%)$ \\
\hline
\end{tabular}

The frequency and percentage of locking in both sides and subluxation in the right side were $3(4.8 \%)$ and 14 $(22.6 \%)$, respectively. The frequency of the subluxation in the left side was 15 (24.2\%) patients.

\begin{tabular}{|c|c|c|c|}
\hline \multirow[t]{2}{*}{ Group } & Sex & right & left \\
\hline & Male & $1(7.1 \%)$ & $1(7.1 \%)$ \\
\hline \multirow[t]{3}{*}{ Case } & Female & $2(4.2 \%)$ & $2(4.2 \%)$ \\
\hline & Total & $3(4.8 \%)$ & $3(4.8 \%)$ \\
\hline & Male & $0(0 \%)$ & $0(0 \%)$ \\
\hline \multirow[t]{2}{*}{ Control } & Female & $0(0 \%)$ & $0(0 \%)$ \\
\hline & Total & $0(0 \%)$ & $0(0 \%)$ \\
\hline
\end{tabular}

Table 9. the frequency and percentage of the subluxation in case and control patients

\begin{tabular}{|l|l|l|l|}
\hline Group & Sex & right & left \\
\hline & Male & $1(7.1 \%)$ & $1(7.1 \%)$ \\
\hline Case & Female & $13(27.1 \%)$ & $14(29.2 \%)$ \\
\hline & Total & $14(22.6 \%)$ & $15(24.2 \%)$ \\
\hline & Male & $0(0 \%)$ & $0(0 \%)$ \\
\hline Control & Female & $0(0 \%)$ & $0(0 \%)$ \\
\hline & Total & $0(0 \%)$ & $0(0 \%)$ \\
\hline
\end{tabular}

The TMJ, which comprises the mandibular condyle, the inferior component, and the temporal bone forming the superior component, is one of the most complex joints in the body (Wu et al. 2012). TMDs are clinically manifested by craniofacial pain in masticatory muscles and other relevant structures, limited mouth opening, and click occurring in the TMJ. (Su et al. 2014). Approximately in $60 \%$ of the population some type of TMD including myofascial dysfunction, internal derangement or degenerative joint disease has been observed. TMD is epidemic in women between 20 and 40 years old (He et al., 2010). In the current study, in the right TMJ of TMD patients, erosion was (27.4\%), osteophyte (17.7\%), subcortical sclerosis (16.1\%), condylar hyperplasia (6.5\%) and flattening (40.3\%). The prevalence of these bone changes in the right TMJ of non-TMD patients was 35.5, 6.5, 3.2, 0 and 37.1\%, respectively. In the left TMJ of the TMD group; erosion was $29.0 \%$, osteophyte $12.9 \%$, subcortical sclerosis $12.9 \%$, condylar hyperplasia 6.5\% and flattening was 37.1\%. The incidence of these bone changes in the left TMJ of non-TMD patients was 22.6, 3.2, 1.6, 0 and 32.3\%, respectively. Significant differences were found for osteophyte incidence in left TMJ, subcortical sclerosis in right TMJ, subcortical sclerosis in left TMJ and condylar hyperplasia in both joints between TMD and non-TMD patients. CBCT provides 
accurate and reliable linear measurements of the dimensions of the mandible and the TMJ because of its nearly 1:1 reconstruction (Honda et al. 2006).

The diagnostic accuracy of CBCT in detecting cortical erosion of the mandibular condyle is greater than that of either linear tomography or panoramic radiography. Its diagnostic properties in assessing bony conditions, therefore, seem to be similar to, or better than other imaging techniques (Hilgers et al. 2005). Until now limited information exists on the role of the CBCT in clinical decision-making in diagnosis or management of disorders of the TMJ (Krishnamoorthy et al. 2013). CBCT has several advantages over CT, such as lower cost, better access to equipment, lower radiation, and diagnostic efficacy as high as CT(but superior than panoramic radiography and linear tomography) (Barghan et al. 2012). CBCT better visualizes bony changes than CT in TMD patients, analyzing lateral slices in isolation and combining coronal and lateral slices (Honey et al. 2007). So, using CBCT imaging technique to assess condylar bone changes was considered for this study.

In a research on association between condylar bone changes revealed in CBCT and clinical dysfunction index in patients with or without TMD, Khojastepour et al. (2017) significant difference reported for the prevalence of all types of bone changes between TMD and nonTMD groups. As well as their report, evaluation of CBCT images in the present study revealed significant differences between TMD and non-TMD condyles (Khojastepour et al. 2017). In a study by Moshfeghi et al. (2012) it was reported that Flattening was the most observed abnormal finding with 16.3\% prevalence. Erosion, condylar hyperplasia, concavity, bifid condyle, condylar hypoplasia and sclerosis were respectively the most common abnormal findings in this study. There were no significant differences in the prevalence of abnormal radiographic findings regarding to the patient's gender, dental status and occlusion, which was in agreement with our report.

Li et al. (2015) studied the characteristics of TMJ in patients with TMD complaints and reported that in the patients with unilateral TMJ pain or joint sounds, the vertical $60^{\circ}$ joint space of the symptomatic side was significantly increased comparing with the asymptomatic side. It is important to note symptoms of TMJ disorders may be observed with normal TMJ and vice versa, which is possibly due to measuring method, age, gender, chewing habits and etc. The condyle and mandibular fossa might differ in shape in subjects with numerous TMD complaints, since shape and function are closely related (Li et al. 2015).

In a similar study, Honey et al. (2007) reported intra observer reliability was moderate $(0.57 \pm 0.22$; range, 0.34-0.78). Pan-N (0.72 \pm 0.15$)$, СВCT $(0.65 \pm 0.21)$ and
CBCT reliability was greater than corrected angle linear tomography. The diagnostic accuracy of CBCT interactively $(0.95 \pm 0.05)$ and CBCT statically $(0.77 \pm 0.17)$ was significantly greater than all other modalities. CBCT interactively was also more accurate than CBCT statically, and Pan-N was more accurate than Pan-TM and corrected angle linear tomography. CBCT images provide superior reliability and greater accuracy than other modalities in the detection of condylar cortical erosion. The CBCT and spiral CT methods were highly reliable for evaluation of the bony mandibular condyle. In the several cases, the bone abnormalities of the autopsy specimens were found with both methods by carefully analyzing all of the images (Honda et al. 2006). Being less expensive and with considerably lower radiation dose in patient examinations, CBCT is both a cost and a dose-effective alternative diagnostic method for examination of the bony components of the TMJ (Honda et al. 2006).

In this regard, Madani et al. (2015) in a recent study using 34 cases for evaluation of degenerative changes, condylar position and joint effusion in patients with TMD via MRI revealed about the condylar position in the fossa that 32 of the examined joints $(47.1 \%)$ were in central position, $30(44.1 \%)$ were in posterior position, and 6 joints (8.8\%) were in the upper position. Moreover, 34 joints (70.8\%) had clicks, and 14 joints (70\%) didn't show clicks or symptoms of osteoarthritis. Following that, grade-zero and grade-one effusions accounted for the highest number of examined joints, and there was no significant relationship between effusion volume and type of clicking. 10 cases (14.7\%) had premature clicks, 20 (29.4\%) had intermediate clicks, and 18 joints (26.5\%) had delayed clicks.

Several radiographic methods are used to assess the TMJ, a field difficult to be imaged due to factors like superimposition of adjacent structures and morphological variations. The complexity of the TMD however, demands a clear and precise image of the region for effective management of the patient. CBCT provides a definite advantage over other techniques due to its low radiation dose to patient, smaller equipment and ability to provide multi-planar reformation and 3D images and there are promising researches in the field of CBCT in TMJ imaging (Krishnamoorthy et al. 2013).

In conclusion, the most prevalent bone changes related to TMD included flattening, erosion and osteophyte. The changes were highly reported for TMD than healthy individuals and no significant correlation was found between TMJ bone changes and the patients' age and gender. Similar comparative studies are needed to demonstrate the full spectrum of TMJ articular dysmorphology and determine whether the accuracy of CBCT remains high. 


\section{REFERENCES}

Alexiou KE, Stamatakis HC, Tsiklakis K.2009 Evaluation of the severity of temporomandibular joint osteoarthritic changes related to age using cone beam computed tomography. Dentomaxillofacial Radiology 38: 141-147.

Barghan S, Tetradis S, Mallya SM: 2012 Application of cone beam computed tomography for assessment of the temporomandibular joints. Aust Dent J 57: 109118

De Boer EWJ, et al. 2014 Value of cone-beam computed tomography in the process of diagnosis and management of disorders of the temporomandibular joint. Br J Oral Maxillofac Surg , http://dx.doi.org/10.1016/j.bjoms.2014.12.007

De Melo DP, Sousa Melo SL, de Andrade Freitas Oliveira LS, de Moraes Ramos-Perez FM, Flores Campos PS. 2014 Evaluation of temporo-mandibular joint disk displacement and its correlation with pain and osseous abnormalities in symptomatic young patients with magnetic resonance imaging. Oral Surg Oral Med Oral Pathol Oral Radiol :1-6

dos Anjos Pontual ML, Freire JSL, Barbosa JMN, Fraza o MAG, dos Anjos Pontual A, Fonseca da Silveira MM. 2012 Evaluation of bone changes in the temporomandibular joint using cone beam CT. Dentomaxillofacial Radiology 41, 24-29.

He SS, Deng X, Wamalwa P, Chen S: 2010 Correlation between centric relation-maximum intercuspation discrepancy and temporomandibular joint dysfunction. Acta Odontol Scand 68: 368376

Hilgers ML, Scarfe WC, Scheetz JP, et al. 2005 Accuracy of linear temporo-mandibular joint measurements with cone beam computed tomographyand digital cephalometric radiography. Am J Orthod Dentofacial Orthop128:803-11.10.

Honda K, Larheim TA, Maruhashi K, et al. 2006 Osseous abnormali-ties of the mandibular condyle: diagnostic reliability of cone beamcomputed tomography compared with helical computed tomogra-phy based on an autopsy material. Dentomaxillofac Radiol 35:152-7.9.

Honey OB, Scarfe WC, Hilgers MJ, et al.2007 Accuracy of conebeam com-puted tomography imaging of the temporomandibular joint: comparisonswith panoramic radiology and linear tomography. Am J Orthod Dentofa-cial Orthop 132:429-38.

Khojastepour L, Vojdani M, Forghani M. 2017 The association between condylar bone changes revealed in cone beam com- puted tomography and clinical dysfunction index in patients with or without temporomandibular joint disorders. Oral Surg Oral Med Oral Pathol Oral Radiol 123:600-605.

Krishnamoorthy B, Mamatha N, Kumar VA. 2013 TMJ imaging by CВСТ:current scenario. Ann Maxillofac Surg 3:80-3.

Ladeira DBS, da Cruz AD, de Almeida SM. 2015 Digital panoramic radiography for diagnosis of the temporomandibular joint: CBCT as the gold standard. Braz Oral Res [online]. 29(1):1-7

Li Y, Guo X, Sun X, Wang N, Xie M, Zhang J, Lv Y, Han W, Hu M, Liu H. 2015 Characteristics of temporomandibular joint in patients with temporomandibular joint complaint. Int J Clin Exp Med 8(9):16057-16063

Ludlow JB, Ivanovic M. 2008 Comparative dosimetry of dental CBCT devicesand 64-slice CT for oral and maxillofacial radiology. Oral Surg Oral MedOral Pathol Oral Radiol Endod 106:106-14.

Madani A.S., Taheri Heravi M., Imani Moghadam M., Chamani A., Javan A., Mirmortazavi A.2015 Evaluation of degenerative changes, condyle position and joint effusion in patients with temporomandibular joint disorder via MRI. Journal of Babol University of Medical Sciences(JBUMS) 17(11):13-20

Moshfeghi M, Amin Tavakoli M, Razaghi Kashani Z, Rafieian N.2012 Abnormal Temporomandibular Joint radiographic findings in patients referred to Department of Oral and Maxillofacial Radiology, Dental School, Shahid Beheshti University of Medical Sciences. J Dent Sch. 29 (5) :381-389.

Su N, Liu Y, Yang X, Luo Z, Shi Z, 2014 Correlation between bony changes measured with cone beam computed tomography and clinical dysfunction index in patients with temporomandibular joint osteoarthritis, Journal of Cranio-Maxillofacial Surgery doi: 10.1016/ j.jcms.2014.04.001.

Wiese M, Wenzel A, Hintze H 2011 Influence of cross-sectional temporo-mandibular joint tomography on diagnosis and management decisionsof patients with temporomandibular joint disorders. J Orofac Pain 25:223-31.

Wu CK, Hsu JT, Shen YW, Chen JH, Shen WC, Fuh LJ: 2012 Assessments of inclinations of the mandibular fossa by computed tomography in an Asian population. Clin Oral Investig 16: 443 450, 